\title{
ESTUDO DE CASO DA INVASÃO DE ANIMAIS EM SUBESTAÇÕES E SEU IMPACTO NA QUALIDADE DO FORNECIMENTO DE ENERGIA ELÉTRICA
}

\author{
Álvaro Pereira Milani - alvaro.milani@energisa.com.br \\ Bruno Flores Farinazzo - brunoflored@icloud.com \\ Fabio Batista de Oliveira - oliveirabf@yahoo.com.br \\ Mateus de Souza Cardoso - mateuscardoso@energisa.com.br \\ Sanderson Rocha de Abreu -sanderson.abreu@unis.edu.br
}

\section{RESUMO}

Este estudo analisa o impacto de ações externas em subestações de energia elétrica de uma Distribuidora de Energia Elétrica do interior do Estado de Minas Gerais, com foco e detalhamento de caso prático causado por animais. Neste contexto, foi abordado no estudo a definição e importância do uso de proteções elétricas no sistema, bem como necessidades de buscas constantes de soluções que mitiguem os prejuízos causados pelos animais invadindo instalações elétricas.

\section{Palavras-Chave:}

Subestação; Energia Elétrica; Proteções Elétricas.

\section{INTRODUÇÃO}

O fornecimento de energia elétrica aos cidadãos é essencial para todos os níveis de atividade, seja residencial, comercial, industrial ou outra a qual se faz necessária, sendo elemento indispensável para o desenvolvimento socioeconômico das nações.

De acordo com a Agência Nacional de Energia Elétrica - ANEEL (2018), temos:

$$
\begin{aligned}
& \text { "O serviço público de distribuição de energia elétrica é realizado por } \\
& \text { concessionárias, permissionárias e autorizadas. Atualmente (2018), temos } 53 \\
& \text { Concessionárias, } 43 \text { Permissionárias e } 13 \text { Autorizadas, totalizando } 109 \text { agentes, } \\
& \text { entre públicos, privados e de economia mista, atuando no mercado de distribuição." }
\end{aligned}
$$

O sistema elétrico como um todo, desde a geração da energia até a efetiva entrega a seu consumidor final, tem a eletricidade percorrida pelas linhas de transmissões e subestações de energia, que posteriormente são transformadas para os níveis de tensão necessário por meio dos transformadores de distribuição.

Abaixo, a figura 1 mostra o "caminho" da energia entre os diversos do setor elétrico, desde à geração da energia, passando pela transmissão e chegando às residências dos consumidores: 
Figura 1 - O sistema de energia elétrica brasileiro

Fonte: IDEC - Instituto brasileiro de defesa do consumidor

As distribuidoras de energia elétrica são responsáveis por garantir a qualidade do fornecimento de energia a seus clientes, sendo as mesmas fiscalizadas e reguladas pela Agência Nacional de Energia Elétrica - ANEEL. No âmbito da qualidade do fornecimento, a ANEEL estabelece diversas normas e regulamentos, dentre eles o PRODIST - Procedimentos de Distribuição, através de seu módulo 8 , que trata as questões relacionadas à qualidade do produto (Seção 8.1) e qualidade do serviço (Seção 8.2).

A qualidade do produto está relacionada à conformidade da tensão entregue aos consumidores e aos fenômenos que podem impactar em seu fornecimento. A qualidade do serviço está relacionada a continuidade da prestação do serviço de fornecimento de energia aos consumidores, sendo este o alvo do trabalho em questão. De acordo com a ANEEL (2018), temos:

"Para a qualidade do produto, este módulo define a terminologia e os indicadores, caracteriza os fenômenos, estabelece os limites ou valores de referência, a metodologia de medição, a gestão das reclamações relativas à conformidade de tensão em regime permanente e às perturbações na forma de onda de tensão e os estudos específicos de qualidade da energia elétrica para fins de acesso aos sistemas de distribuição." e

"Para a qualidade do fornecimento de energia elétrica, este módulo estabelece a metodologia para apuração dos indicadores de continuidade e dos tempos de atendimento a ocorrências emergenciais, definindo padrões e responsabilidades." 
Este estudo tem como objetivo entender a função das subestações de energia elétrica, bem como os impactos que sua interrupção - com destaque em interrupções por intervenções de animais, podem ocasionar à sociedade e no desenvolvimento regional.

Considerando que as intervenções de animais nos equipamentos elétricos causam desde prejuízos nos ativos da Distribuidora, compensações financeiras a serem pagas aos clientes até a acidentes fatais, esse estudo torna-se extremamente relevante e seu objetivo final é identificar oportunidades de ganhos quantitativos e qualitativos através de análise de ferramentas disponíveis no mercado, bem como estudo para desenvolvimento de ferramentas novas que possam ser agregadoras a este cenário.

\section{REVISÃO DE LITERATURA}

\subsection{Indicadores de Desempenho Global de Continuidade}

De acordo com PRODIST - Módulo 8, seção 8.2, capítulo 5, subitem 5.8.5, anualmente é realizada a apuração dos DGC - Desempenho Global de Continuidade pelo órgão regulador, à ANEEL, e publicado até abril de cada ano. Este indicador consiste na razão dos valores realizados por seus respectivos limites, e após sua apuração compõe o ranking da continuidade onde as empresas são classificadas, de acordo com a quantidade de clientes e o índice realizado (quanto menor o DGC melhor a empresa se mostrou no período de apuração). Conforme cita a ANEEL (2016), “(...), o DGC visa comparar o desempenho de uma distribuidora em relação às demais empresas do país. $\mathrm{O}$ indicador permite avaliar o nível da continuidade da distribuidora (...)".

A importância de estar mais bem colocado no ranking da continuidade vai além simplesmente do índice apurado, mas também da possibilidade de ganhos financeiros pelo melhor desempenho, através do Componente Q do Fator X. Segundo a ANEEL (2015), "O Fator $\mathrm{X}$ tem como objetivo primordial a garantia de que o equilíbrio estabelecido na revisão tarifária entre receitas e despesas eficientes seja mantido nos reposicionamentos tarifários subsequentes". O componente Q por sua vez, visa ser mecanismo de incentivo a melhoria da qualidade do serviço prestado pelas distribuidoras, conforme ANEEL (2015) através do PRORET - Procedimentos de Regulação Tarifária, Módulo 2, Submódulos 2.5 e 2.5A, de acordo com o ano da revisão tarifária da distribuidora.

Desta forma, diante de um cenário de competição e comparação de resultados, as empresas Distribuidoras de energia buscam rotineiramente desenvolver soluções que mitiguem o impacto de eventos externos que impactem em interrupções à seus clientes e seus indicadores de continuidade, de forma a garantir o cumprimento dos índices de qualidade do fornecimento (DEC e FEC), impostos pelo órgão regulador.

De acordo com o exposto, o PRODIST Módulo 8 é subdividido em duas seções, onde será mais bem explorada a seção 2, referente a Qualidade do Serviço prestado pelas Distribuidoras em termos de duração (DIC-DMIC-DEC) e frequência (FIC-FEC). Segundo PRODIST, Módulo 8, Seção 8.2 (2018), temos:

○ DIC - Duração de Interrupção Individual por Unidade Consumidora ou por Ponto de Conexão, expressa em horas e centésimos de hora;

- FIC - Frequência de Interrupção Individual por Unidade Consumidora ou por Ponto de Conexão, expressa em número de interrupções e centésimos do número de interrupções; 
○ DMIC - Duração máxima de Interrupção Contínua por Unidade Consumidora ou por Ponto de Conexão expressa em horas e centésimos de hora;

- DEC - Duração Equivalente de Interrupção por Unidade Consumidora, expressa em horas e centésimos de hora;

○ FEC - Frequência Equivalente de interrupção por Unidade Consumidora, expressa em número de interrupções e centésimos do número de interrupções.

Conforme exposto, a apuração dos indicadores de continuidade é realizada de forma individualizada (DIC e FIC) e, através destes é realizada a consolidação dos indicadores coletivos, que medem a duração e a frequência média que cada unidade consumidora do conjunto de unidades consumidoras considerado teve descontinuidade da distribuição de energia elétrica. Abaixo, seguem as fórmulas de cálculo do DEC e FEC, conforme PRODIST Módulo 8, seção 8.2, item 5.5 (2018):

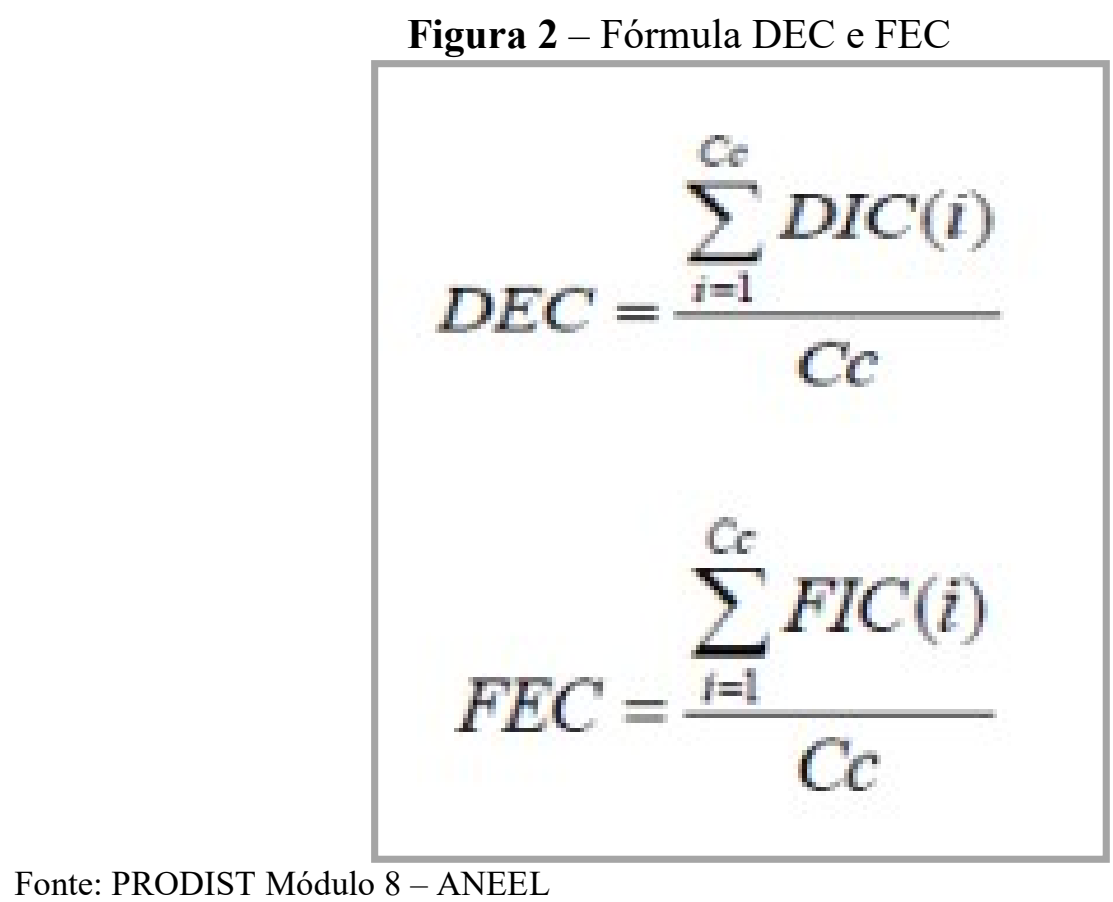

Onde:

$\mathrm{i}$ = índice de unidade consumidoras atendidas em BT ou MT faturadas do conjunto;

$\mathrm{Cc}=$ número total de unidades consumidoras faturadas do conjunto no período de apuração, atendidas em BT ou MT;

Para o correto entendimento do cálculo dos indicadores de continuidade coletivos é necessária a compreensão do conceito de agrupamento dos consumidores de cada área de concessão. Conforme PRODIST - Módulo 1 (2008), temos a descrição de conjunto de unidades consumidoras como "Agrupamento de unidades consumidoras, aprovado pela ANEEL e pertencente a uma mesma área de concessão ou permissão".

Atualmente, a regra de formação de conjuntos de unidades consumidoras ou conjuntos elétricos tem relação com as Subestações de Distribuição (SED) e os critérios para formação dos mesmos, conforma PRODIST Módulo 8, são: 
i. Abrangência do conjunto deve ser as redes MT à jusante da SED e de propriedade da distribuidora.

ii. SED que possuam números de unidades consumidoras igual ou inferior a 1.000 clientes devem ser agrupadas a outras, formando um único conjunto.

iii. SED com número de unidades consumidoras superior a 1.000 e igual ou superior a 10.000 podem ser agregadas a outras, formando um único conjunto.

iv. A agregação de SED deve obedecer ao critério de contiguidade das áreas.

v. É vedada a agregação de duas ou mais SED cujos números de unidades consumidoras sejam superiores a 10.000

vi. Mediante aprovação da ANEEL, poderão formar diferentes conjuntos SED que atendam a áreas não contíguas, ou que atendam a subestações MT/MT.

Adicional aos itens citados acima, existem outros critérios que tratam situações específicas e exceções. Cabe destacar que para cada conjunto elétrico existem limites regulatórios para os indicadores de continuidade (DEC e FEC), ou seja, definição de indicadores máximos que em média as unidades consumidoras de determinados conjuntos podem ter seu fornecimento interrompido e por um tempo máximo determinado.

Conforme ANEEL (2015), a definição de limites é a criação de "Indicadores definidos pela ANEEL para aferir a qualidade do fornecimento de energia elétrica no conjunto de unidades consumidoras da área de atuação de cada distribuidora. Consideram a duração e frequência das interrupções no fornecimento do serviço". Estes limites são definidos através da realização de audiências públicas em fase de revisões tarifárias, por concessionária, que ocorrem de 4 em 4 anos ou de 5 em 5 anos, a depender do contrato de concessão de cada distribuidora. Após as revisões tarifárias, são publicadas resoluções autorizativas com os limites de DEC e FEC para cada conjunto.

\section{METODOLOGIA}

A pesquisa a qual se refere este estudo está pautada no acervo disponível em meios digitais, como artigos científicos publicados em renomados congressos do Setor Elétrico, conteúdo dos órgãos reguladores (Agência Nacional de Energia Elétrica - ANEEL e Ministério de Minas e Energia), dados técnicos de registros de ocorrência de Distribuidora de Energia Elétrica do interior de Minas Gerais, buscando identificar as ocorrências significativas e o impacto aos consumidores.

\section{CARACTERIZAÇÃO DO PROBLEMA}

Segundo Costa et al. (2008, p.1), as Distribuidoras de Energia Elétrica passaram a estudar métodos para evitar a incidência de pássaros e outros animais em suas subestações de energia, de modo a reduzir os prejuízos com queima de ativos elétricos, pagamento de compensação por descumprimento de indicadores de continuidade, bem como mitigar a insatisfação de seus consumidores.

O Quadro 1 apresenta o quantitativo de ocorrências, registrado no período entre 2017 e 2020 e o número relevante de clientes atingidos por interrupções causadas por animais em que acessaram subestações de energia elétrica de uma determinada Distribuidora de energia 
elétrica do interior de Minas Gerais, com concessão para fornecimento a 450 mil consumidores.

Quadro 1 - Registro de Ocorrências x Clientes afetados por interrupções de energia causadas por animais em subestações de energia elétrica.

\begin{tabular}{|c|c|c|c|}
\hline Ano & $\begin{array}{c}\text { Quantidade } \\
\text { de Ocorrências }\end{array}$ & $\begin{array}{c}\text { Quantidade de } \\
\text { Clientes Afetados }\end{array}$ & $\begin{array}{c}\text { \% de clientes afetados } \\
\text { em relação ao total } \\
\text { de clientes da } \\
\text { Distribuidora }\end{array}$ \\
\hline 2017 & 6 & 110.163 & $24,48 \%$ \\
\hline 2018 & 6 & 81.975 & $18,22 \%$ \\
\hline 2019 & 9 & 153.210 & $34,05 \%$ \\
\hline $\begin{array}{c}\text { 2020 } \\
\text { (Janeiro a Maio) }\end{array}$ & 4 & 65.283 & $14,51 \%$ \\
\hline $\begin{array}{c}\text { Estimativa } \\
2020\end{array}$ & 10 & 156.678 & $34,82 \%$ \\
\hline Total & $\mathbf{2 5}$ & $\mathbf{4 1 0 . 6 3 1}$ & - \\
\hline
\end{tabular}

Fonte: Distribuidora de energia elétrica do interior de Minas Gerais

No período da análise, mais de 410 mil clientes foram afetados diretamente por ocorrências do gênero deste estudo, o equivalente a uma média de quase 10 mil clientes por mês, atingidos pela interferência de animais na operação da distribuição de energia.

\subsection{Impacto de invasão de animais em uma subestação de energia elétrica}

As ocorrências de interrupção em subestações de distribuição são causadas por pássaros e pequenos animais, como gambás, ouriço-cacheiro e pombos. Além da interrupção do fornecimento de energia elétrica aos consumidores e perda de receita para a Distribuidora, geralmente, as ocorrências são acompanhadas por arcos elétricos extremamente destrutivos, ocasionando danos, na maioria dos casos, em equipamentos, barramentos, isoladores, além da morte dos animais.

Destaca-se neste estudo um caso prático, ocorrido em 26/06/2020, em uma cidade da zona da mata mineira, onde o desarme de uma Subestação de energia elétrica da Distribuidora local ocorreu por um curto-circuito provocado pelo pouso de um pombo no barramento elétrico. Na ocasião, a subestação desarmou por atuação da proteção. Devido a automatização do subsistema de distribuição, houve a manobra automatizada na rede de forma imediata, transferindo a carga daquela subestação para um circuito auxiliar. $O$ desarme da subestação afetou 20 mil clientes em um intervalo de tempo de 27 segundos, entre o curto-circuito e a conclusão da manobra automatizada.

Devido ao incidente ocorrido, a Distribuidora necessitou deslocar equipe especializada para inspeção e aferição do estado de seus ativos elétricos. Para esta ocorrência, foi identificada a queima do isolador de proteção, sendo efetuada a substituição imediatamente. Ocorre que o processo de transferência de carga causou sobrecarga no alimentador que recebeu a carga, causando o rompimento dos cabos por sobrecorrente, causando ainda mais 
prejuízos - tanto para a Distribuidora quanto para os clientes que estavam conectado àquele circuito elétrico.

Esse fato tem forte impacto negativo na satisfação dos clientes, já que a indisponibilidade da energia elétrica em um determinado período afeta a rotina e trazem prejuízos aos consumidores de todas as classes de consumo. Delgado (2002) cita alguns prejuízos passíveis de ocorrer no processo produtivo de indústrias, como: interrupção da produção, perda de matéria-prima, substituição e manutenção de equipamentos e custo de religamento dos equipamentos.

Relevante destacar neste caso em epígrafe a atuação e importância das proteções elétricas que reduziram a abrangência, impactos e prejuízos aos demais ativos elétricos da Distribuidora. Segundo a Prof. ${ }^{a}$ Ruth Leão, "O princípio básico de proteção é a técnica de selecionar, coordenar, ajustar e aplicar os vários equipamentos e dispositivos protetores a um sistema elétrico, de forma a guardar entre si uma determinada relação, tal que uma anormalidade no sistema possa ser isolada, sem que outras partes do mesmo sejam afetadas".

Para ilustrar que esta realidade impacta à várias Distribuidoras, aFigura 3, mostrada abaixo,reune várias notícias onde houve interrupção no fornecimento de energia elétrica causada por animais adentrando subestações de energia elétrica.

Figura 3 - Notícias sobre interrupções provocadas por animais em subestações

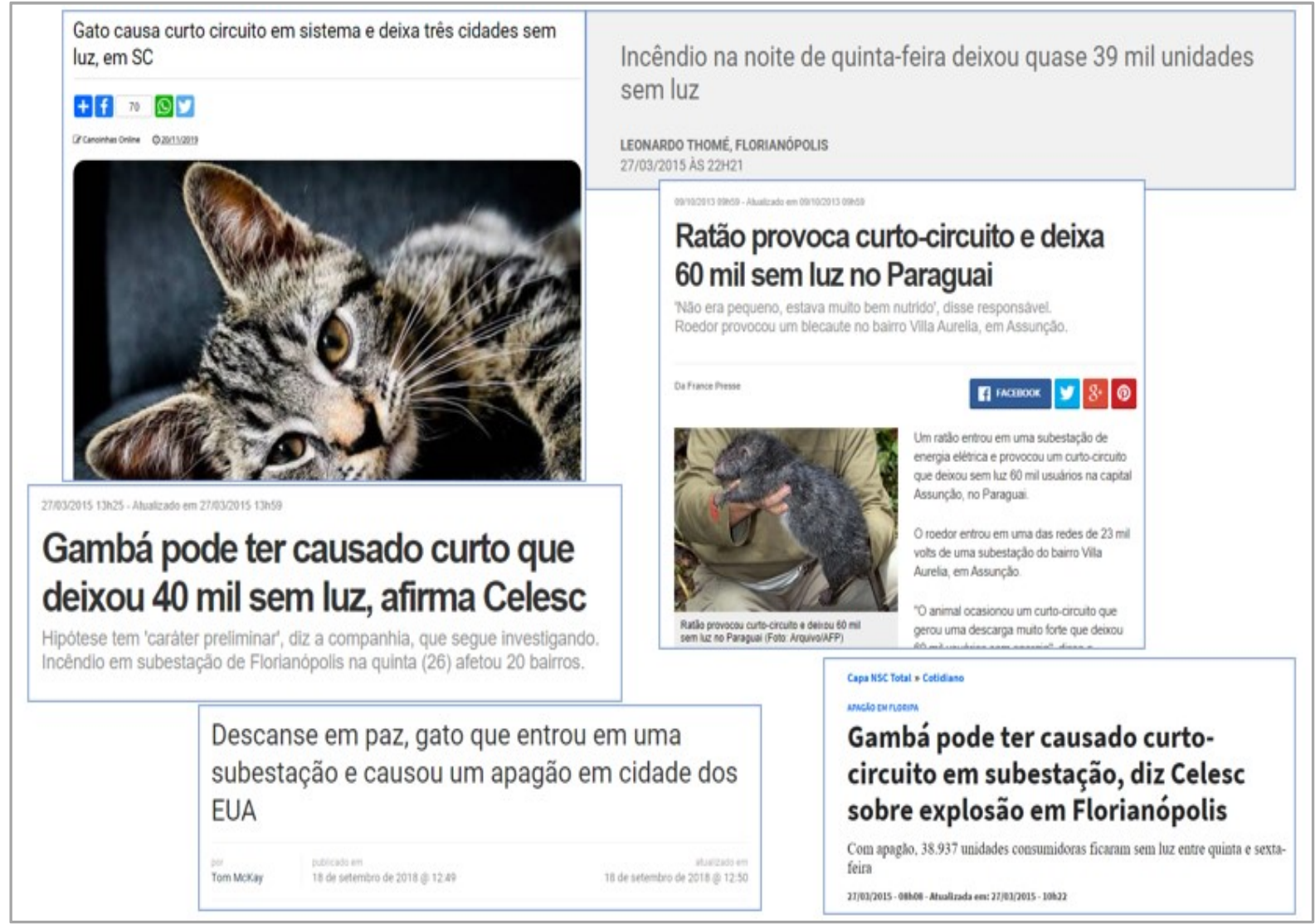

Fonte: Internet

\section{AÇÕES PARA MITIGIAR A INVASÃO DE ANIMAIS NAS SUBESTAÇÕES}

Como já discutido amplamente neste estudo, existem fortes evidências de que a invasão de animais em equipamentos elétricos representaalto risco àdescontinuidade do serviço de prestação de energia elétrica aos consumidores, bem como custos associados a 
danos aos equipamentos. Sendo assim, destaca-se algumas ações utilizadas por Distribuidoras, no que tange ao assunto:

- Estátua de Gavião: utilizada para reduzir incidência de pássaros nas subestações, bem como fezes em equipamentos.

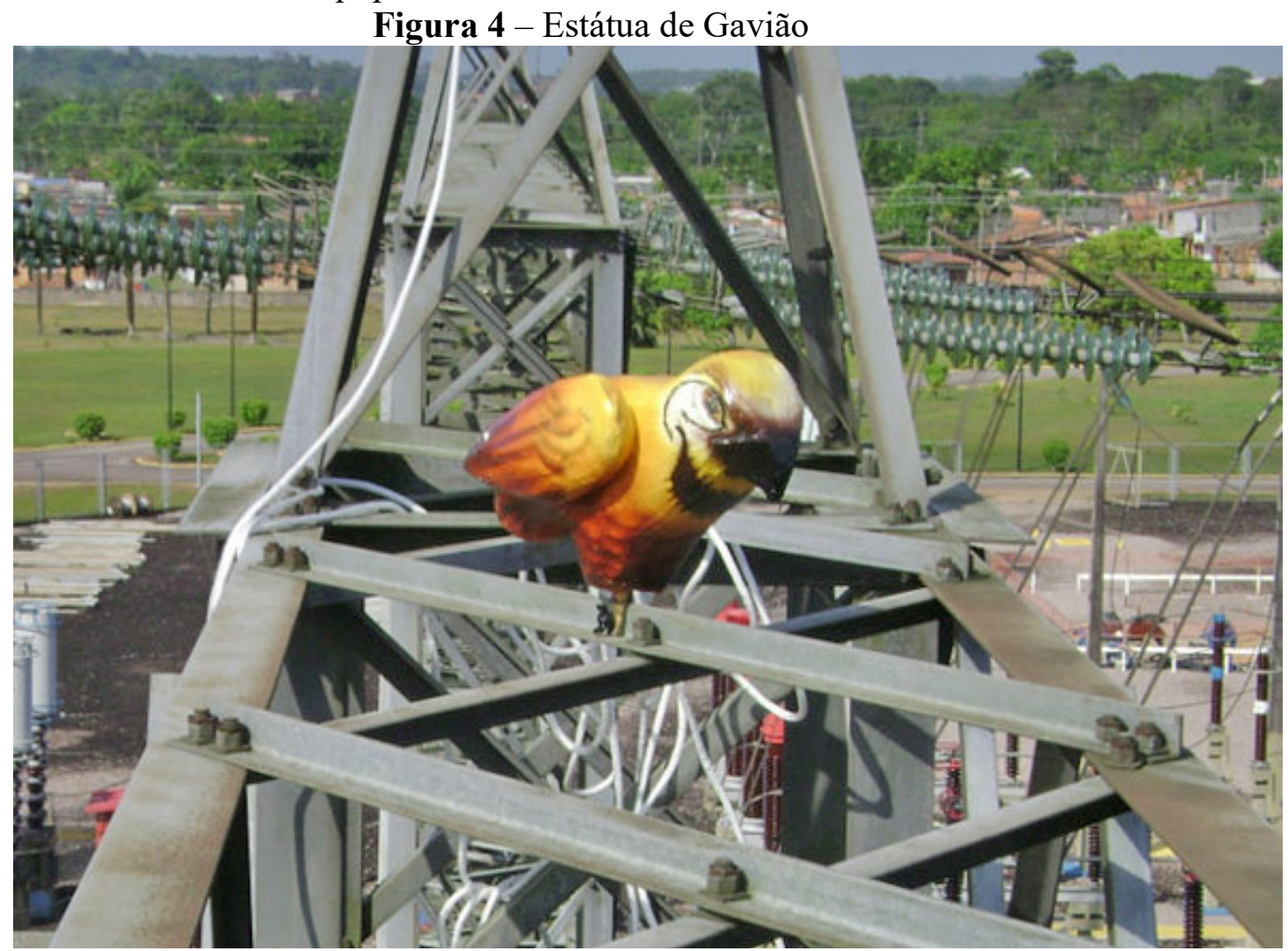

Fonte: Portal G1

Conforme detalhado no artigo em epígrafe, há reincidências de ocorrências causadas por pássaros na rede. Segundo notícia publicada no Portal G1 (2009), uma distribuidora de energia elétrica implementou esta estátua de gavião com objetivo de "intimidar" estes animais, reduzindo os custos com limpezas de fezes de andorinhas e faltas de energia e a Distribuidora obteve ganhos na ordem de R \$276mil com a limpeza das fezes de andorinhas.

Numa Distribuidora da Zona da Mata de Minas foi realizado um piloto em uma subestação localizado na cidade de Cataguases-MG, onde nos 6 primeiros meses foi observada melhoria no quantitativo de ocorrências de pombos fechando curto no barramento e demais equipamentos da subestação, contudo, com o tempo, mesmo com o gavião instalado ainda ocorrem eventos de natureza animal, em específico "pombos" gerando interrupções no fornecimento de energia da região. Desta forma, esta alternativa se mostrou ineficaz para sua realidade e o projeto não foi implantado nas demais subestações da Empresa.

- Barreira Metálica: utilizada para impedir aproximação de animais silvestres nos equipamentos, evitando incidência de curto-circuito. 
Figura 5 - Foto de barreira metálica próxima aos equipamentos elétricos

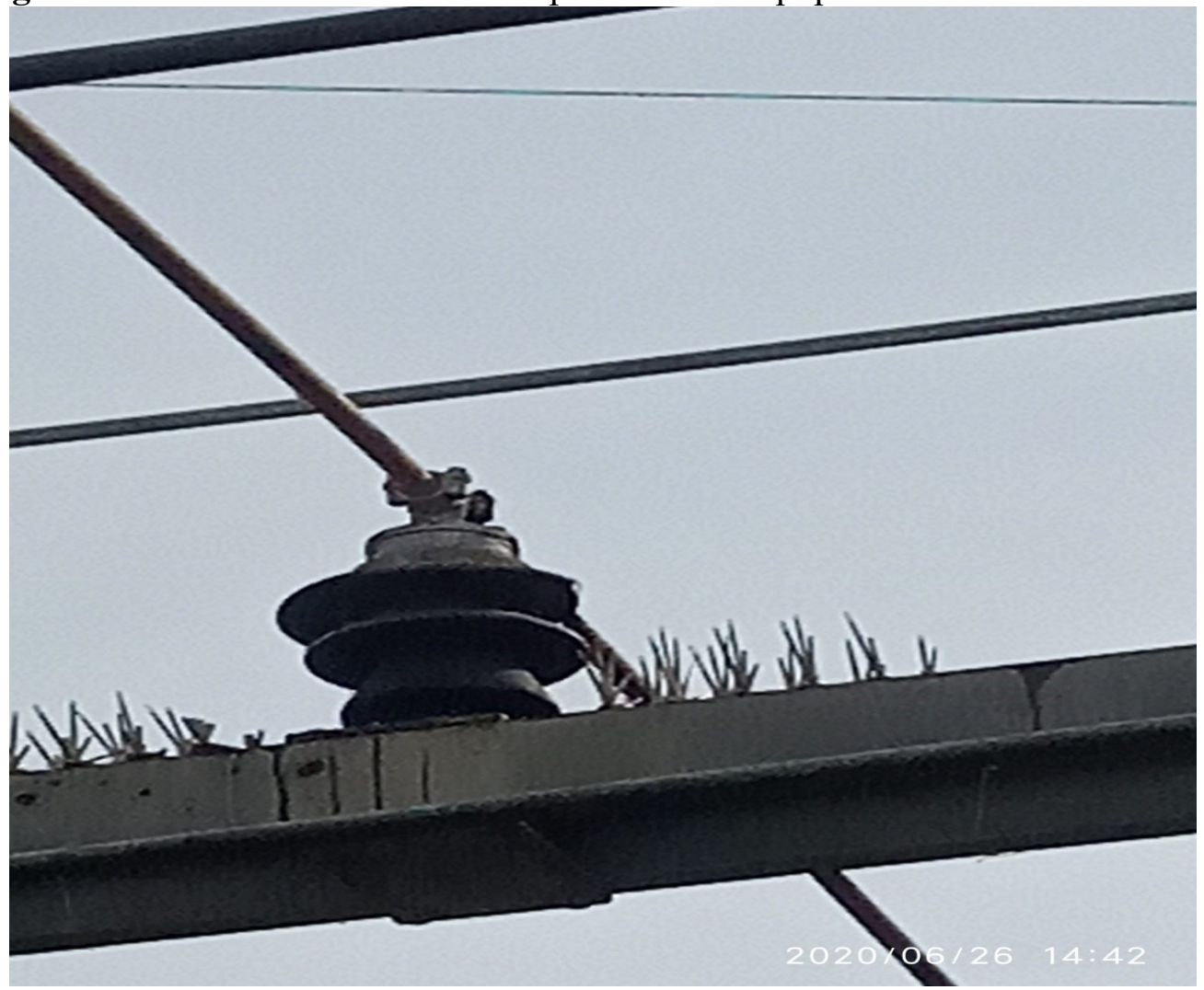

Fonte: Próprios autores (2020)

É possível identificar na figura 5 que há pontos metálicos antes e depois dos equipamentos elétricos, buscando coibir o acesso de animais aos ativos.A aplicação das garras fixadas às estruturas garante que, caso haja acesso dos animais, eles evitem se aproximar dos equipamentos. O ideal, entretanto, é impedir de maneira definitiva o acesso dos animais já na base das estruturas.

- Instalação de chapa de aço galvanizada na base das estruturas: Segundo artigo publicado no SENDI 2008 - o maior Seminário de Energia Elétrica do Brasil, a utilização da chapa de aço galvanizada protege os pés das estruturas, reguladores de tensão e transformadores de aterramento, evitando que animais as escalem, consequentemente reduzem o acesso deles aos equipamentos elétricos. 
Figura 6 - Base das estruturas de $13,8 \mathrm{KV}$ com caixas metálicas contra animais

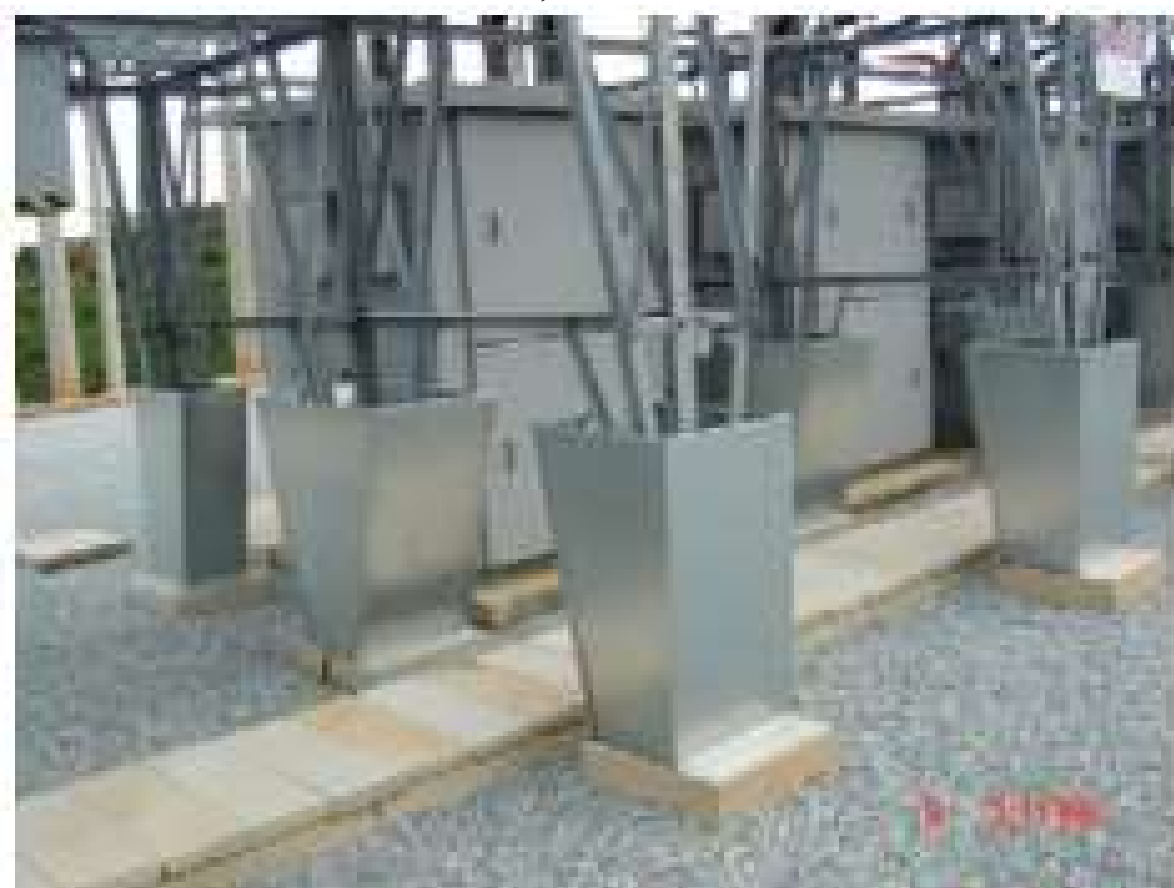

Fonte: XVIII Seminário Nacional de Distribuição de Energia Elétrica (2020)

Após aplicação da solução da Figura 6, foi analisado na sequência o retorno do investimento - que abrange diversas outras iniciativas, e constatou-se no estudo que o mesmo se deu em aproximadamente 4 anos, além do destaque positivo nos resultados operacionais atingidos referente ao período entre 2006 e 2008, onde não foram registradas novas ocorrências com animais em ativos elétricos de subestação, trazendo diversos benefícios operacionais através de uma solução padronizada eficiente, além deminimizar os impactosà fauna e flora.

Fonte: SENDI (2008)

Quadro 2 - Análise de payback

\begin{tabular}{|c|c|}
\hline \multicolumn{2}{|c|}{$\begin{array}{c}\text { SE IBIÁ 2 - ANÁLISE DE RETORNO DO } \\
\text { INVESTIMENTO DO PROJETO PILOTO } \\
\text { Ref.: dez/2007 }\end{array}$} \\
\hline $\begin{array}{c}\text { NÚMERO DE } \\
\text { DESLIGAMENTOS DE I } \\
\text { HORA/ANO }\end{array}$ & RETORNO ( ANOS) \\
\hline 1 & 6,7 \\
\hline 2 & 3,3 \\
\hline 3 & 2,2 \\
\hline 4 & 1,6 \\
\hline Custo da hora do desligamento: R\$ 28.946,00 \\
\hline Custo total: RS 195.716.00
\end{tabular}

- Instalação de PVC nos pés de estruturas e conexões de equipamentos: utilizada para impedir a escalada de animais nos pórticos e fechar curtos em conexões/buchas de equipamentos. 
Figura 7 - Pés das estruturas e conexões / buchas com a instalação de PVCs

Fonte: Próprios autores (2020)

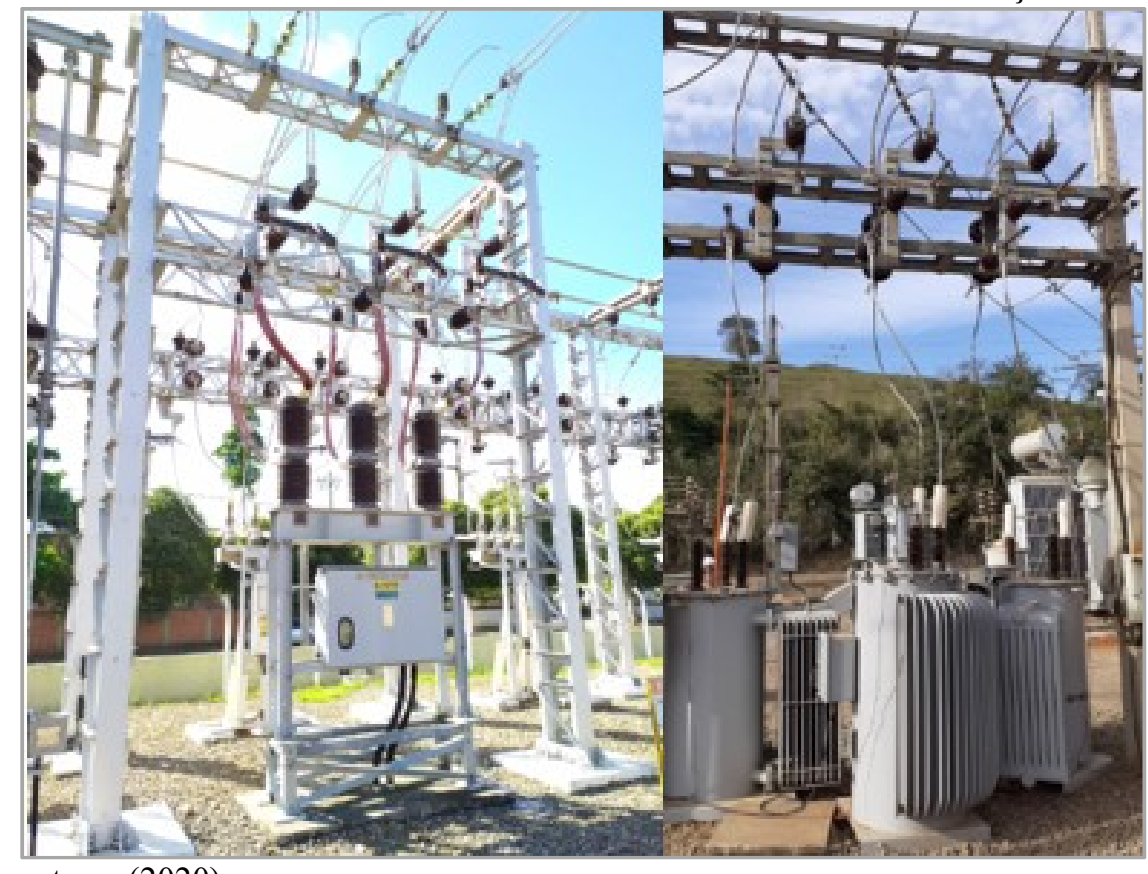

Na mesma linha da instalação das chapas galvanizadas apresentado anteriormente, esta possibilidade também busca eliminar o risco de escalada de animais nas estruturas / pórticos das subestações, contudo, com valores bem menores.

$\mathrm{Na}$ Distribuidora da Zona da Mata de Minas foi elaborado projeto de instalação destes tubos de PVC em suas subestações ao longo de 2020 e os ganhos relacionados a esta possibilidade serão mais bem avaliados a partir de 2021 .

\section{CONCLUSÃO}

De acordo com as análises permitidas neste estudo, foi possível identificar os relevantes impactos - tanto à população quanto à Distribuidoras, causados por invasão de animais em subestações de energia elétrica. É possível também compreender a importância da coordenação e seletividade das proteções elétricas para evitar prejuízos maiores e a redução da abrangência das ocorrências.

De posse dos dados, foi elaborado uma pesquisa no acervo digital de algumas práticas existentes, que buscam mitigar a incidência de animais e pássaros nos ativos elétricos das subestações e identificado que há diversas soluções propostas neste âmbito de estudo.

Algumas ações, como a da Estátua de Gavião, deixa uma impressão inicial de que há efeito positivo na eliminação de acessos de pássaros.Entretanto, há o que se discutir em relação ao tempo de uso. É necessário um estudo mais abrangente para identificar se estes pássaros e/ou pombos não se "habituarão" e até mesmo pousar sob elas.

O estudo publicado no SENDI 2008 demonstra algumas soluções de sucesso no combate ao escalamento de animais nas estruturas metálicas e foi discriminado neste estudo como ponto referencial. De fato, há de se concluir que com a aplicação da base galvanizada haverá reduçãoda aderência da pegada dos animais e, logicamente, evitarão que eles acessem as partes superiores onde estão localizados os ativos elétricos. Nesta mesma vertente foi 
possível observar outro trabalho com a instalação de canos PVC nas bases de pórticos e em conexões / buchas de equipamentos.

Sendo assim, conclui-se este artigo com boas práticas identificadas no acervo digital, bem como demonstra a constante necessidade de buscas de soluções ágeis e robustas para garantir uma confiabilidade ainda maior do sistema elétrico brasileiro, garantindo satisfação aos consumidores e eficiência financeira às Distribuidoras. Deve ser avaliado no mercado outras soluções tecnológicas como sonares e pastas contra pombos, assim como soluções simples como melhorias em cercas, instalação de cercas elétricas entre outras possibilidades de forma a buscar sempre melhoria no combate a animais em subestações causando interrupções no fornecimento de energia elétrica a consumidores. A exploração de práticas e o desenvolvimento de outras ainda não existentes devem ser realizadas de forma contínua, dando sequência e este importante trabalho. 


\section{REFERÊNCIAS BIBLIOGRÁFICAS}

AGÊNCIA NACIONAL DE ENERGIA ELÉTRICA - ANEEL. Serviço Público de Distribuição de Energia Elétrica. Disponível em: https://www.aneel.gov.br/distribuicao2 Acesso em 25 de junho de 2020.

AGÊNCIA NACIONAL DE ENERGIA ELÉTRICA - ANEEL. PRODIST Módulo 8. Disponível em: https://www.aneel.gov.br/modulo-8. Acesso em 15 de maio de 2020.

AGÊNCIA NACIONAL DE ENERGIA ELÉTRICA - ANEEL. PRODIST Módulo 8. Disponível em: https://www.aneel.gov.br/documents/656827/14866914/M\%C3\%B3dulo_8-Revis\%C3\%A3o_10/2f7cb862e9d7-3295-729a-b619ac6baab9. Acesso em 25 de junho de 2020.

AGÊNCIA NACIONAL DE ENERGIA ELÉTRICA - ANEEL. DGC - Desempenho Global de Continuidade (Ranking ANEEL-2019). Disponível em: https://www.aneel.gov.br/ranking-2019. Acesso em 13 de abril de 2020 .

AGÊNCIA NACIONAL DE ENERGIA ELÉTRICA - ANEEL. PRORET - Submódulo 2.5A.Acesso em 13 de abril de 2020 .

AGÊNCIA NACIONAL DE ENERGIA ELÉTRICA - ANEEL. PRORET - Submódulo 2.5. Disponível em: https://www.aneel.gov.br/proret-submodulos/-/asset_publisher/9GaPoqtgd9GK/content/submodulo-25/654800?inheritRedirect=false\&redirect $=\mathrm{http} \% 3 \mathrm{~A} \% 2 \mathrm{~F} \% 2 \mathrm{Fwww}$.aneel.gov.br\%2Fproretsubmodulos\%3Fp_p_id\%3D101_INSTANCE_9GaPoqtgd9GK\%26p_p_lifecycle\%3D0\%26p_p_state\%3Dnorm al\%26p_p_mode\%3Dview\%26p_p_col_id\%3Dcolumn-2\%26p_p_col_count\%3D1.Acesso em 13 de abril de 2020 .

Canoinhas online - "Gato causa curto circuito em sistema e deixa três cidades sem luz, em SC". Disponível em: https://www.canoinhasonline.com.br/2019/11/gato-causa-curto-circuito-em-sistema-e.html Acesso em 25 de junho e 2020

COSTA, P. R. F. et al. Redução de curto-circuitos provocados por pequenos animais nas subestações da Cemig. 2008. Disponível em: http://www.cgti.org.br/publicacoes/wpcontent/uploads/2016/01/Reduc\%CC\%A7a\%CC\%83o-de-Curtos-Circuitos-Provocados-por-Pequenos-Animaisnas-Subestac\%CC\%A7o\%CC\%83es-da-CEMIG.pdf. Acesso em 22 junho de 2020.

DELGADO, J. D. B, 2002. "Gestão da qualidade total aplicada ao sector do fornecimento da energia eléctrica”. Dissertação de Doutorado, Universidade de Coimbra. Setembro de 2012.

Folha de Londrina - “Gambá provoca curto-circuito". Disponível em: https://www.folhadelondrina.com.br/cidades/gamba-provoca-curto-circuito-333703.htmlAcesso em 25 de junho e 2020

INSTITUTO BRASILEIRO DE DEFESA DO CONSUMIDOR. O Sistema de Energia Brasileiro: Nacional e Integrado. Disponível em: https://idec.org.br/edasuaconta/sistema. Acesso em 25 de junho de 2020.

LEÃO, Ruth. Departamento de Engenharia Elétrica - Universidade Federal do Ceará. Distribuição de Energia Elétrica, capítulo 4.4 Disponível em: https://edisciplinas.usp.br/pluginfile.php/130060/mod_resource/content/1/Subestacoes-texto.pdf. Acesso em 22 junho de 2020.

ND+ - "Incêndio na noite de quinta-feira deixou quase 39 mil unidades sem luz". Disponível em: https://ndmais.com.br/noticias/incidentes-com-curtos-circuitos-e-fogo-sao-raros-em-subestacoes-de-energia-deflorianopolis/ Acesso em 25 de junho e 2020 
Portal G1 - “Gavião de mentira é usado para espantar andorinhas em Belém”. Disponível em: http://g1.globo.com/Noticias/Brasil/0,,MUL1255593-5598,00-

GAVIAO+DE+MENTIRA+E+USADO+PARA+ESPANTAR+ANDORINHAS+EM+BELEM.html. Acesso em 28 de maio de 2020 .

Portal G1 - "Ratão provoca curto-circuito e deixa 60mil sem luz no Paraguai". Disponível em: http://g1.globo.com/planeta-bizarro/noticia/2013/10/ratao-provoca-curto-circuito-e-deixa-60-mil-sem-luz-noparaguai.htmlAcesso em 25 de junho e 2020

Portal G1 - "Gambá pode ter causado curto que deixou 40mil sem luz, afirma CELESC". Disponível em: http://g1.globo.com/sc/santa-catarina/noticia/2015/03/gamba-pode-ter-causado-curto-que-deixou-40-mil-semluz-diz-celesc.htmlAcesso em 25 de junho e 2020

SENDI 2008 - Redução de Curtos-Circuitos Provocados por Pequenos Animais nas Subestações da CEMIG. Disponível em: http://www.cgti.org.br/publicacoes/wpcontent/uploads/2016/01/Reduc\%CC\%A7a\%CC\%83o-de-Curtos-Circuitos-Provocados-por-Pequenos-Animaisnas-Subestac\%CC\%A7o\%CC\%83es-da-CEMIG.pdf. Acesso em 17 de maio de 2020.

UOL - "Descanse em paz, gato que entrou em uma subestação e causou um apagão em cidade dos EUA". Disponível em : https://gizmodo.uol.com.br/gato-apagao-new-orleans/ Acesso em 25 de junho e 2020 